\title{
RECORDANDO A JOHN MURRA, EN SU HOMENAJE ${ }^{1}$
}

\author{
Silvia Palomeque ${ }^{2}$
}

Homenajear a John, intentando hacerlo en la forma en que a él le hubiera gustado, nos obliga a recuperar su propia vida en tanto la consideraba como su mejor escuela. Homenajear a John, tal como él hubiera querido, nos implica también recuperarlo desde nuestros propios recuerdos trayendo hacia nosotros la historia del momento cuando él incidió sobre el destino de nuestra vida.

John Murra nació en Odesa, Ucrania, el 24 de agosto de 1916. Se reconocía como rumano por haber vivido allí desde muy pequeño y junto a su familia. De origen modesto, su padre y su tío habían sido criados y educados en un orfelinato debido a la pobreza en que los dejó el temprano fallecimiento de un abuelo reparador de relojes. Aficionado al fútbol cuando era joven, con mucho talento para los idiomas -que estudió por presión de su padre-, ávido lector, inserto en un mundo multiétnico, pronto se integró al Partido Comunista con gran convencimiento. Durante las entrevistas de $1993^{1}$, John mencionaba que ingresó al comunismo sin críticas, “... cuando el comunismo viene, viene como consecuencia de lo que yo era...”, nos dirá. Su amigo Petru, líder de las juventudes comunistas, un poco mayor que él, pasó a ser su “...modelo de varón...”. De él John dirá que fue “...la primera persona que puedo respetar en lo humano...”, quizá para remarcar lo endeble que era la relación con un padre respetado pero lejano y la importancia que tuvo su inserción en una estructura distinta a la de su familia. Petru y su hermana menor, que lo sobrevivió, fueron sus afectos más fuertes.

En su adolescencia, perseguido por su accionar político, lo expulsaron del liceo, trabajó en fábricas de papel en Rumania y Croacia junto a campesinos-obreros, terminó preso algunas veces (1933 y 1934) y, a sus 18 años, terminó en Chicago junto a un tío músico, cuando él aún no tenía ni idea de que podía ganarse la vida observando y clasificando la diversidad étnica en la que había vivido inmerso.

En Chicago continuó más preocupado de la militancia política que de los estudios formales, obteniendo una primera graduación en sociología (1936) con notas no muy meritorias pero con una experiencia que le permitió decidir que su interés estaba en la antropología y no en la sociología. Casi inmediatamente, a los 20 años de edad, en un corto período de meses, se casó, se inscribió en antropología, comenzó los cursos y le dijo "sî́" a la autoridad del Partido Comunista que vino a reclutarlo para ir a luchar a España.

Entre sus 20 y 23 años de edad (1937 a 1939) participó en las Brigadas Internacionales que defendían la República durante la Guerra Civil Española contra la derecha. Las serias dificultades de comunicación que enfrentaban en la reunión semanal del Estado Mayor conformado por Comisarios de distintas naciones que hablaban diferentes lenguas, hicieron que la participación de este joven militante en la Guerra Civil Española terminara siendo la de traductor; una seria y compleja responsabilidad que le brindó la posibilidad de conocer las decisiones centrales sobre la política y la guerra, y también participar en un espacio donde tenían que organizar creativamente las relaciones entre militantes de múltiples nacionalidades y diversos grupos sociales.

Como en la Guerra Civil pasaba la mayor parte del tiempo trabajando en el Estado Mayor, partió sin permiso a luchar en el frente siendo luego sancionado, para finalmente terminar herido, preso y trasladado tardíamente -junto a cientos de camaradas- a Francia donde colaboró en mejorar la infraestructura buscando paliar las pésimas condiciones de alojamiento y alimentación. Logró partir hacia Chicago justo antes de que los alemanes entraran y fusilaran a los que aún quedaban allí.

\footnotetext{
1 Versión revisada de la Conferencia en Homenaje a John Víctor Murra, a un año de su fallecimiento, el 16 de octubre de 2006, a los 90 años. XVI Congreso Nacional de Arqueología Argentina, Jujuy, 11 de octubre de 2007.

2 CONICET y UNCba, Argentina. silviapalomeque@gmail.com
} 
En todas sus conversaciones y en sus entrevistas del 93, John recuperaba a la guerra como su mejor formación, más que a las universidades, y también recordaba que la experiencia que adquirió durante la misma le permitió romper definitivamente con el Partido Comunista y enfrentar sus primeras responsabilidades de adulto. De esta experiencia provino su futura dedicación, con exclusividad, a la antropología, sabiendo que desde allí podía desplegar sus preocupaciones humanitarias junto a su respeto a lo diverso.

De regreso a Estados Unidos, se dedicó a estudiar seriamente pero debía hacerlo en medio de las múltiples tareas que necesitaba hacer para sobrevivir. En estos años fue que viajó al Ecuador (1941) y descubrió “ ...la civilización andina como logro humano fundamental...", su interés en estudiarla y, además "...ser su partidario". Realizó una primera tesis de maestría que obtuvo excelentes calificaciones y planteó el proyecto de tesis doctoral sobre los incas. Impedido de viajar a los Andes porque durante el maccartismo lo dejaron sin pasaporte por ser un "rojo", para su tesis doctoral recurrió a la consulta y sistematización de la información ofrecida por las crónicas. Para sobrevivir desarrollaba todo tipo de tareas, lavando cerámica para los arqueólogos, haciendo traducciones, etc., todo lo cual va relatando al mismo tiempo que marca las pésimas relaciones laborales que soportaban los colegas no doctorados en las universidades norteamericanas, con sus puestos inestables y mal pagos.

A nuestro entender, durante este período, su interés y dedicación por las sociedades andinas corría parejo con su preocupación por los estudios africanos, por esas sociedades y sus fuertes procesos de cambio. Sobre estos temas dictaba clases con gran éxito entre los jóvenes a quienes los llevaba a comparar etnografías con novelas que incluían descripciones etnográficas, mientras asesoraba políticamente a los nacientes movimientos independentistas africanos sobre cómo solucionar los problemas de diversidad étnica en la conformación de los nuevos estados y sobre sus negociaciones con los organismos internacionales donde también participaban sus antiguas metrópolis.

Hacia el final de ese período, con una tesis doctoral demorada, autocriticando su comportamiento personal, genera un plan para doctorarse antes de sus 40 años. Fue así que finalmente logró defenderla y aprobarla luego de diez años de trabajo, en 1955, con el apoyo del sicoanalista al que le dedicó la tesis, que era su antiguo camarada y sargento de batallón en España. En esta tesis que fue y será un aporte invalorable, que careció de director, por primera vez se analizó al Imperio Inca centrándose en el ayllu andino y en su creativa y particular forma de organización productiva y en su acceso a los diversos recursos requeridos para su reproducción.

Tal como él lo previó, a partir de su tesis obtendrá mejores trabajos, que le permitirán dedicarse a investigar y -después de recuperar su pasaporteconsultar el Archivo del Cusco entre 1958 y 1959. A nuestro entender, para él tuvo mucha importancia su preocupación sobre los países africanos que antes remarcábamos ya que, en 1962, postuló a un trabajo en Yoruba al mismo tiempo que diseñaba el proyecto de Huánuco. Recién frente a un primer rechazo de los africanos decidió optar por el proyecto de Huánuco y luego, cuando lo aceptaron en una segunda instancia, él ya está trabajando en Perú.

En Huánuco ya es el John Murra que conocemos, el que construyó toda una compleja e intensa red de relaciones académicas y personales que abarcó no sólo Perú sino también Ecuador, Chile, Bolivia y Argentina, y quien -inserto en estas relaciones y manteniendo su trabajo en Estados Unidos- publicó todas las "visitas" e invalorables interpretaciones, trabajos que siempre nos dicen algo nuevo durante la necesaria relectura que se nos impone luego de percibir que, durante la revisión anterior, su lenguaje simple y claro nos hizo caer en la trampa de haber sentido que comprendíamos todo.

En esta ocasión he vuelto a releer a John buscando precisar y sistematizar sus importantes aportes. Lo primero que obtuve de esa relectura fue la certeza sobre mi dificultad para comprenderlo plenamente en su producción intelectual y caer en la cuenta de que, al menos para mí, este proceso quedará siempre inconcluso. Releer a John siempre me será muy enriquecedor y, además de seguir aprendiendo, me brindará el inmenso placer de recordarlo. La certeza sobre la imposibilidad de una comprensión plena de su obra, en parte, deriva de mi oficio de historiadora en historia económica y social, que nunca se formó como antropóloga a pesar de su insistencia. Ello constituye una limitación abismal para entender varios aspectos de su obra. Percibir estas limitaciones me permitió tomar la decisión de escribir este texto en su homenaje desde mi perspectiva, como historiadora, mientras reenvío hacia otros trabajos ${ }^{2}$ a los lectores interesados en conocer sus aportes como antropólogo. 
Conocí a John Murra ya jubilado, recién en 1984, cuando él tenía 68 años y yo 37, como profesor de la Primera Maestría en Historia Andina de FLACSO Quito, una primera experiencia de formación en historia del espacio andino, no de cada país andino, que en ello recuperaba sus propuestas. Salvo un español, todos los estudiantes proveníamos de los países andinos o habíamos estado viviendo en alguno de ellos casi una década. Veníamos graduados en distintas disciplinas, y tal como se hacía en FLACSO en esos años, estábamos becados a tiempo completo para dedicarnos al trabajo en una maestría que derivaba de un proyecto académico "andino", no del interés mercantil institucional.

No sabíamos si John iba a venir o no, recién nos aceptó como alumnos hacia el final del curso, luego de haber tomado clases con Lumbreras, Assadourian, Platt, Fontana, Salomon, Morner y Moreno Yáñez, entre otros. El profesor Murra llegó en el momento justo en que la mayor parte de los alumnos habíamos roto no solo con los límites disciplinarios sino también con los espacios académicos de origen y, con un poco de pavor, habíamos logrado percibir algo del complejo mundo de la diversidad cultural andina, de las especificidades del sistema de dominación colonial y de las persistencias y transformaciones de las sociedades posteriores a la ruptura del vínculo colonial, mientras nadie sabía muy bien qué hacer con todo ello. Alguna vez John me dijo que nunca tuvo un diálogo con alumnos tan ávidos y yo, al pasar los años, me di cuenta que él apareció ante nosotros recién cuando estábamos listos para él.

Gran parte de los alumnos que optamos por cursar su seminario en el año 1984 éramos parte de la militancia de izquierda latinoamericana de los años sesenta y setenta que acabábamos de ser derrotados militarmente por las derechas y que, además, estábamos en pleno proceso de revisión de la intensa y dura experiencia pasada. Como en años anteriores el estudio de las ciencias sociales se había dado la mano con la militancia política, también enfrentábamos serios problemas en nuestros trabajos y quizá eso había incidido en que optáramos por ser alumnos de la maestría. Los instrumentos de análisis conocidos segmentaban la sociedad en base a conceptos provenientes de la economía política, donde las estructuras económicas predominaban sobre todo el conjunto social y llevaban a la división clásica de la sociedad en clases sociales. Durante los 70, en medio de la vorágine de los movimientos sociales, ya se había avanzado en la crítica al evolucionismo y la obligatoria sucesión de modos de producción. Pero en los instrumentos de análisis se había llegado sólo a aceptar que aparte de la estructura económica existía una superestructura política y que ambas podían tener movimientos autónomos. En el análisis del mundo rural se había logrado recuperar a Chajanov y se aceptaba la existencia de sectores campesinos con sus unidades domésticas y su lógica propia de reproducción económica. Es decir, un conjunto de avances que no modificaban la homogeneidad inicial dada por lo económico, que sólo complejizaban parcialmente el panorama. Esos instrumentos no sólo eran reduccionistas sino también insuficientes para nosotros, personas de origen militante, que hacían trabajo de campo o archivo centrando su análisis en los sectores "populares" o "campesinos" andinos y que, para peor, estaban bastante cuestionados sobre el qué hacer con los saberes que lograban alcanzar.

Cuando en 1999 Victoria Castro, Carlos Aldunate y Jorge Hidalgo presentaron las entrevistas de 1993, si bien acotaron el accionar de John al decir que su batalla consistía en "...mostrar logros culturales donde los otros sólo ven pobreza...”, sí están señalando el tipo de batalla que John nos ayudó a librar a nosotros en 1984. John Murra, en las entrevistas de 1993, les dice que para "mostrar" primero hay que "ver" pero que para él, "el ver" era algo obvio. “...Es obvio que los gansos tienen dos patas, pero antes hay que ver gansos...", dirá. Pero lo que a John le parece una obviedad, su capacidad de "ver" y "mostrar", dos palabras claves en su accionar, no eran fáciles de desentrañar para nosotros en 1984. Yo todavía entiendo que "ver" dista de ser sencillo, y también observo que incluso a él no le fue fácil encontrar el camino del "mostrar".

Para 1984 nosotros ya habíamos visto gansos, pero "gansos pobres", porque eso es lo que sabíamos ver los militantes de izquierda, y también por eso nos sentíamos tan cómodos con John. Al igual que él veíamos los gansos y sin desconocer que había pavos reales, nos fijábamos en los gansos como él cuando optaba por ver las papas en vez de fijarse más en el maíz. Ambas eran opciones políticas, se trataba de centrarse en algo y dejar en segundo plano el resto, aunque sin dejar de considerarlo. Y esto también se relaciona con su tan mentada pelea con el comunismo, que yo aclararía que a mi entender sólo fue con la cúpula de un Partido Comunista estalinista o con determinado tipo de dirigentes, pero no lo fue en absoluto con sus 
antiguos camaradas o combatientes que siguieron siendo sus amigos y conformando la red donde vivía inserto. Su ruptura no fue con los anarquistas ni con el POUM (Partido Obrero de Unificación Marxista), con quienes estuvo de acuerdo cuando organizaron cooperativas en España o cuando iniciaron la reforma agraria, avances destruidos por el Partido Comunista estalinista que sostenía que sólo había que mantener la república, y no profundizar los ideales revolucionarios. Nosotros en el 84 entendíamos de todo esto, nadie tenía que explicarnos mucho; porque si bien en los movimientos políticos de los años sesenta y setenta no se había avanzado tanto como los anarquistas y el POUM en España, ya habíamos tenido suficientes fricciones con el PC como para que la experiencia de John nos resultara familiar.

Pero si bien nosotros habíamos visto los gansos, lo concreto es que no habíamos visto los mismos gansos de John, en tanto nos centrábamos en diferenciar los gansos entre ricos y pobres y en sus lógicas internas, no pudiendo ver sus diferencias no económicas. Aun con dificultades ante la profundidad temporal de los procesos, los únicos que podían ver mejor que nosotros eran los escasos antropólogos del grupo; ellos sí podían ver, aunque luego no sabían qué hacer con su mirada. Lo que los no antropólogos no podíamos ver era a las sociedades andinas en su diversidad, con sus ayllus, con sus importantes logros culturales interrumpidos o trastocados por la invasión española que las sometió a un régimen de dominación colonial, que mantuvieron sus autoridades étnicas porque mientras los españoles trataban de usarlas para explotarlos, porque las unidades domésticas de los ayllus durante siglos sólo acataban las autoridades de sus propias jefaturas, las que elegían o aceptaban en un proceso de selección interno que aún desconocemos, y cuyas consecuencias continúan luego de la ruptura del pacto colonial e incluso inciden en la configuración de las propias elites dominantes.

El poder percibir esas diferencias culturales entrelazadas con la dominación colonial, que hacían sumamente diferentes a los ayllus indígenas de los campesinos europeos clasificados en base a criterios económicos y clasistas en los que basábamos nuestros análisis, todo eso, sólo fue posible gracias a la labor de John Murra y de sus discípulos o colegas cercanos, y para ello fue necesario un largo año de cursos y esfuerzos y desestructurante reflexión que afectó luego toda nuestra relación con el mundo. Desde una perspectiva historiográfica, fue un avance más que importante, que a muchos de nosotros nos abrió otro mundo, la posibilidad de pensar la historia desde una perspectiva no sólo distinta a la del poder (que ya la teníamos) sino poder comenzar a penetrar en las lógicas -no en la lógica- de las sociedades andinas y tratar de reconstruir sus especificidades, pensando en la existencia de un pensamiento propio, de propuestas alternativas a las de las elites y cuáles serían. Es decir incluir las dudas de la antropología dentro del pensamiento histórico y trabajar junto a arqueólogos, antropólogos y etnógrafos, o formarse para realizar el trabajo recuperando las mejores tradiciones de esas disciplinas, no todas.

Entiendo que a través de su trayectoria crítica, de ruptura con la dirección del Partido Comunista y sus políticas, de su desestructuración como militante de "Partido", eso que nosotros entendíamos tan bien, el reubicarnos en un terreno conocido y común, fue lo que le permitió a John plantearnos su opción política de vida, de volverse antropólogo como oficio de vida militante, en tanto existía un tipo de disciplina antropológica (la que ejercían aquellos que aprendían el idioma de la gente que estudiaban) que permitía conocer las “.... 8000 soluciones diversas a los mismos problemas humanos, de los cuales cada sociedad escoge su propia solución...".

Durante ese curso, en una conversación que tuvimos luego de devolvernos nuestros exámenes finales, logramos exponer sobre lo confuso que se presentaba nuestro futuro, quizá buscando un consejo sin decirlo explícitamente. Fue un diálogo muy pero muy difícil de nuestra parte, debido a su habilidad habitual para que termináramos analizando los elementos naturalizados que incluían nuestras propias preguntas, antes de darnos una respuesta parcial que finalmente tendía a señalarnos los caminos a recorrer para que construyéramos nuestra propia respuesta. No recuerdo bien hasta dónde habló él o logró que nosotros concluyéramos sobre la necesidad de "el ver" y luego "el mostrar", en vez de nuestro habitual "transformar, en nombre de...", todo un problema que tampoco le fue fácil resolver a él, a mi entender. De allí salió la necesidad de que a futuro ocupáramos nuestros lugares, que reflexionáramos sobre que teníamos el pequeño poder de la palabra con cierta autoridad y que quizá ella lograra algo de escucha social; que luego de ver y respetar, viéramos de usar nuestro poder de palabra para mostrar al conjunto social los logros 
culturales de los diversos grupos andinos, pero sólo durante el lapso durante el cual éstos aún no pudieran expresarse por sí mismos. También allí percibimos que la utopía social de John, su meta esperable, era la de un mundo de gente diversa y asumida como tal, con capacidad de expresar directamente su situación y sus intereses, y luchar por ellos. Esas fueron las conclusiones políticas que yo recuerdo que sacamos de esa primera e intensa relación con él y fue allí donde, personalmente, comenzamos una relación fuerte y duradera muy significativa para mí en tanto se convirtió en una persona querida y amiga con quien compartíamos el mismo lenguaje básico de relación con el mundo.

Para culminar cabe remarcar que su compromiso fue con el mundo, como un combatiente de las brigadas internacionales, su pelea contra la discriminación la desarrolló en todos los lugares que vivió, a favor de los afronorteamericanos, con los españoles, con los africanos, con las mujeres y principalmente con las sociedades andinas y sus logros. Parte central de su vida fue su compromiso con la humanidad en la búsqueda de un futuro diferente, una alternativa a construir, diferente de la dominada por la mercancía y el éxito comercial, una sociedad solidaria donde se valoren el talento y el trabajo digno, sin discriminación, y yo creo que también por un mundo con predominio de mujeres trabajadoras, creativas, inteligentes, solidarias y con capacidad para generar instituciones que permitan la continuidad de la transformación más allá de la vida de una persona, para permitir la formación de jóvenes que garanticen, que posibiliten, la recreación y continuidad de esta opción de vida y de trabajo de inigualable valor que nos ha dejado como legado.

\section{Referencias Citadas}

Castro, V., C. Aldunate y J. Hidalgo, editores 2000 [1993] Nispa Ninchis/decimos diciendo: conversaciones con John Murra. IEP: IAR, Lima.

Lorandi, A.M.

2006 Homenaje al Maestro John Murra. Cuadernos de Historia, Serie Economía y Sociedad, Area de Historia del CIFyH-UNC 8:5-8.

Presta, A.M.

2007 De la militancia a la escritura de la historia. Contextos, temas y problemas en la renovación de los estudios andinos.
Ponencia presentada en el Simposio los Asesinos de la Memoria "Homenaje a los historiadores que vivieron las vicisitudes del siglo $X X$ ". FFyL, UBA, 27 y 28 de agosto de 2007.

Rowe, J.H.

1984 An interview with John V. Murra. Hispanic American Historical Review 64:4, 1984, pp. 633-653 (con varias traducciones al español en internet).

Notas

1 Castro et al. 2000. Nos remitiremos principalmente a esas entrevistas de 1993, debido a que John estaba muy satisfecho de ellas. La corta biografía la fui construyendo a medida que extraía y ordenaba cronológicamente los datos que él fue dispersando a lo largo de las entrevistas. Si bien he tratado de respetar cómo él quería que se recordara su vida, obviamente, el texto también incluye mi respetuosa y afectuosa mirada, el cómo yo lo veía.

2 J.H. Rowe 1984; Castro, et al. 2000; A.M. Lorandi 2007 y A.M. Presta 2007. 
